\title{
NEW DISTRIBUTION RECORD FOR WATER SCORPIONS (HEMIPTERA: NEPIDAE) FROM ALBERTA
}

\author{
Curtis Farrus ${ }^{1}$, Vytenis Gotceitas ${ }^{2}$
}

${ }^{1} 5813$ 49A Street, Vegreville, AB, T9C $1 \mathrm{H} 2$.

2Department of Environmental Sciences, Lakeland College, 5707 College Drive, Vermilion, AB, T9X 1K5, E-mail: <Vee.Gotceitas@lakelandcollege.ca>

During a field trip with students enrolled in the 'Environmental Monitoring and Protection' course at Lakeland College, Alberta, to the Alberta side of Cypress Hills Interprovincial Park, a water scorpion specimen (Ranatra fusca Palisot) was collected while sampling for aquatic invertebrates in Spruce Coulee Reservoir on 24 September 2011 (Figs. 1 and 2). This not only represents a first record of this genus and species of aquatic Hemiptera in Alberta, but also of any member of the Family Nepidae (K. Fry, Entomological Society of Alberta; D. Shpeley, University of Alberta; G. G. E. Scudder, University of British Columbia, pers. comm.). ${ }^{1}$ Collection of this specimen brings the number of identified families of aquatic Hemiptera in Alberta to nine. ${ }^{1}$

Ranatra fusca has been reported as being the most widespread and common species of Ranatra in North America. ${ }^{2}$ Distribution maps for $R$. fusca published by Sites and Polhemus (1994) indicate the presence of this species in southern Alberta; ${ }^{2}$ however, as these authors themselves state with regard to these distributional maps: "In some instances, entire areas have been shaded regardless of whether or not a particular species has been recorded from every part of each region included. Although isolated state or provincial records may be nonexistent, these species probably do occur in most of the shaded areas where suitable habitat is found." Prior to the collection of our specimen, in Canada, specimens of $R$. fusca have been collected from Nova Scotia, Prince Edward Island, New Brunswick, Quebec, Ontario, Manitoba, Saskatchewan, and British Columbia. ${ }^{3,4}$ In the United States, $R$. fusca has been recorded throughout the northern states and south to North Carolina and Kansas, and along the west coast south and around to Texas. ${ }^{2}$

All members of the family Nepidae have two long, slender, caudal filaments that fit together to form a breathing tube, with which the animal obtains atmospheric air by pushing the tip of the tube through the water surface. ${ }^{5}$ Nepids are predators, and the forelegs are modified for striking out and seizing prey, while the middle and hind pairs of legs are used to cling and move about on aquatic vegetation. ${ }^{4,5}$ Nepids are ambush predators, which typically sit motionless, or move about slowly, on aquatic vegetation. ${ }^{2}$ Members of the genus Ranatra are reported to typically be 
found in lentic systems in association with aquatic vegetation. ${ }^{2,4}$ Ranatra spp. have five larval instars, and the eggs, larvae, and adults all live in the water. Ranatra spp. have a thin, narrow, elongate body (i.e. adult $R$. fusca $\geq 50 \mathrm{~mm}$ in length from head to tip of respiratory tubes), ${ }^{2}$ which along with a typical brownish colouration and their habit of sitting motionless, or moving about slowly, gives them the appearance of a piece of dead vegetation (Fig. 2). Specimens of Ranatra are known to demonstrate death-feigning behaviour, making them appear very sticklike and, therefore, difficult to detect in a sample. ${ }^{2}$ When material collected by sweeping a dip-net through the vegetation is placed in water, as was the case in our sampling (i.e. white plastic basin), much of the plant material sinks while specimens of
Ranatra often float to the surface or start to move, at which time they are more readily detected.

Our specimen of $R$. fusca was collected from a well-vegetated shoreline habitat (i.e. emergent and submergent aquatic vegetation) in Spruce Coulee Reservoir

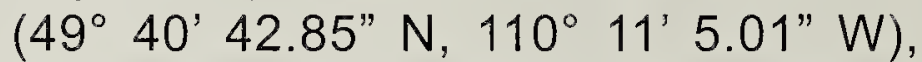
just below the campsite in Cypress Hills Interprovincial Park (Fig. 1). The nearest other Canadian collection record to ours is in Saskatchewan from the Wood River near Gravelbourg (49 $54^{\prime} 07^{\prime \prime} \mathrm{N}, 106^{\circ}$ 29' 48" W), approximately $275 \mathrm{~km}$ east of Spruce Coulee Reservoir. ${ }^{4}$ Adult Ranatra are winged and are known to disperse nocturnally among suitable water bodies. ${ }^{2}$ Therefore, the specimen of $R$. fusca collected in Spruce Coulee Reservoir

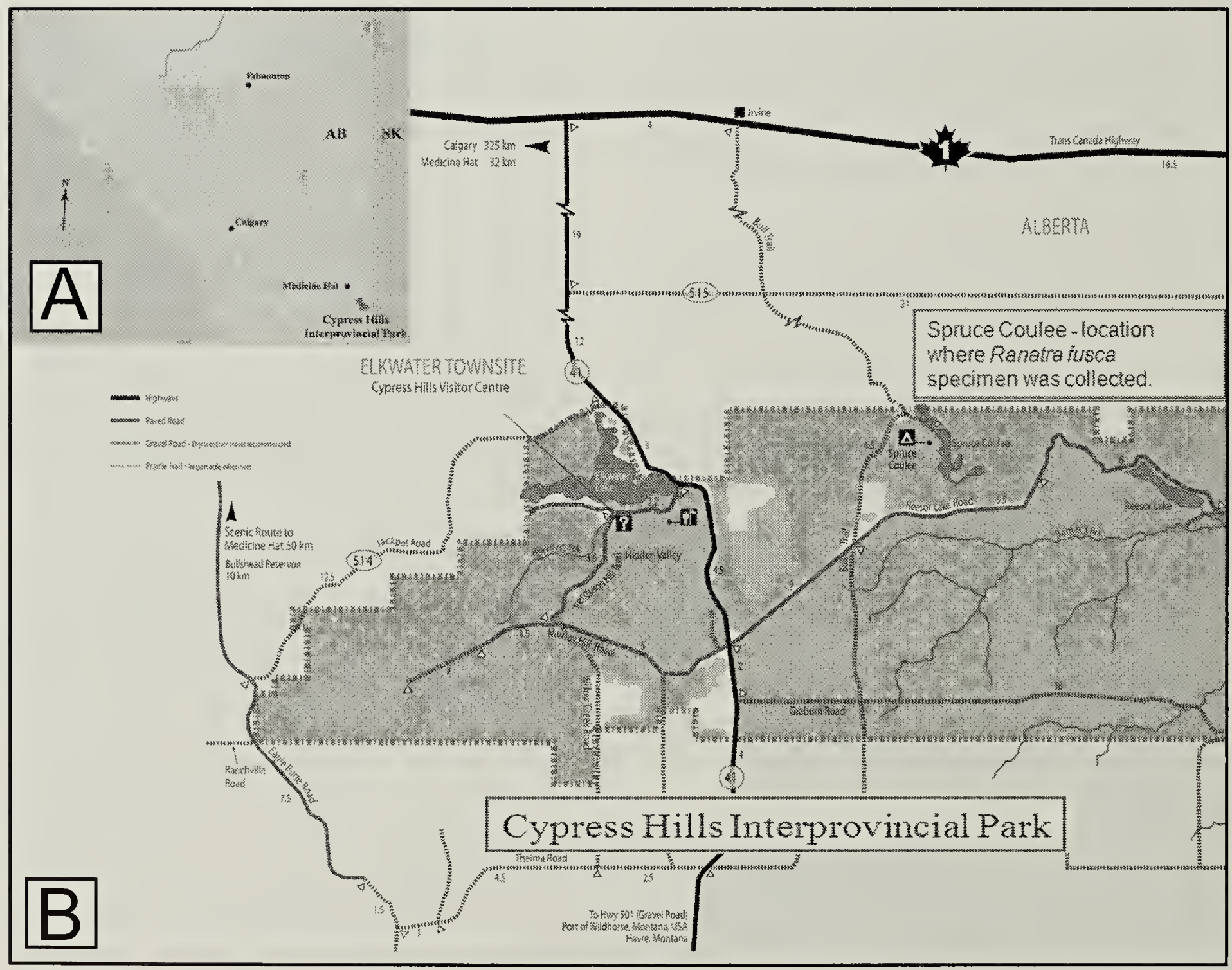

Figure 1. (A) Location of Cypress Hills Interprovincial Park in Alberta. (B) Site where a specimen of Ranatra fusca was collected in the park (i.e. Spruce Coulee). 


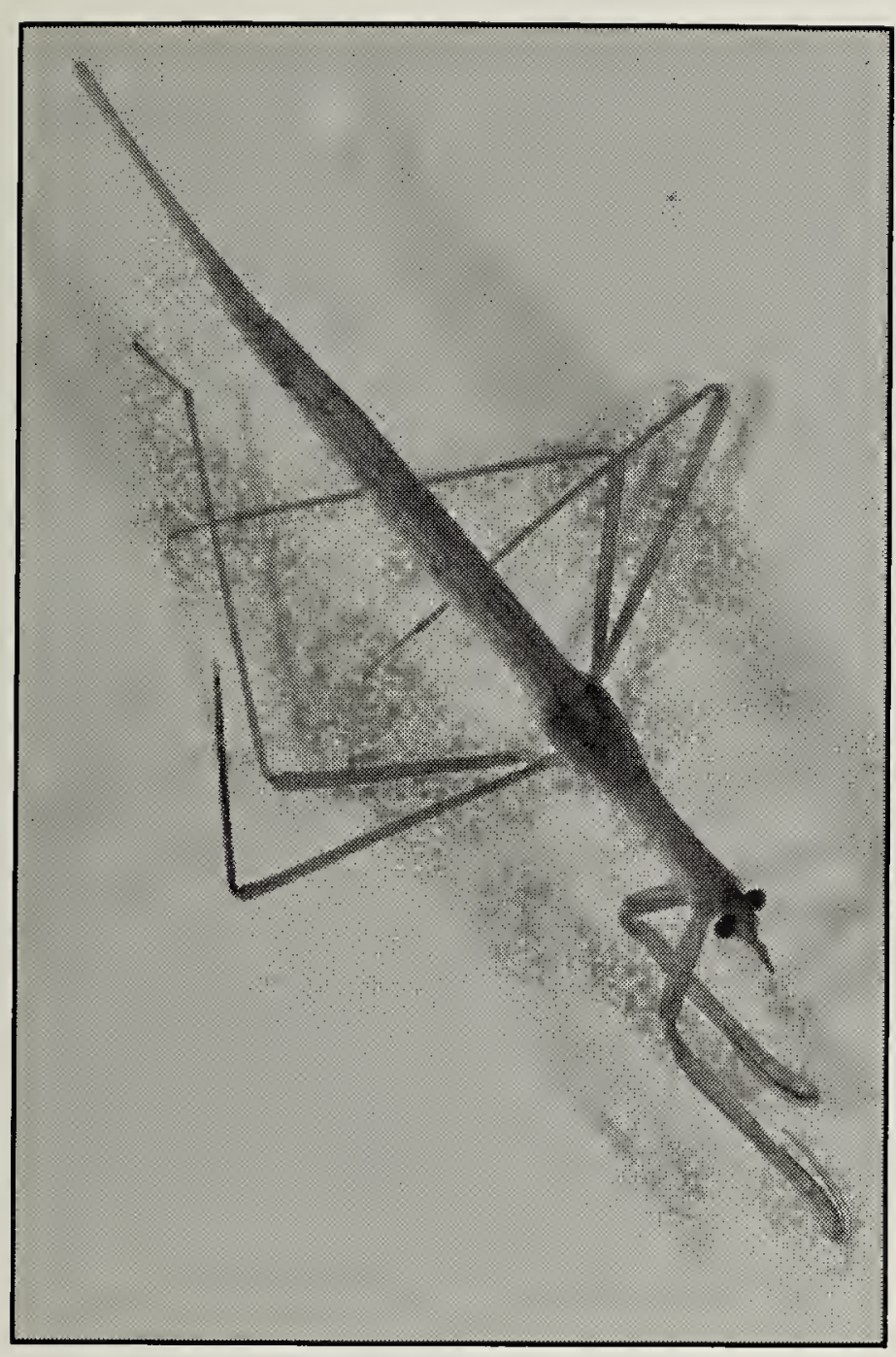

Figure 2. Photograph of the actual specimen of Ranatra fusca collected in the park.

Jim Zadorozny

could have been a transient. However, the specimen we collected was an immature, fourth-instar larva (G. G. E. Scudder, pers. comm.), and as such did not have fully developed wings at the time of collection. The presence of an immature specimen of $R$. fusca in Spruce Coulee Reservoir would suggest that there is an actual breeding population of these animals in this system.

\section{Acknowledgements}

We thank the following individuals for their assistance in determining that our specimen is indeed a new record for Alberta: Dr. G. G. E. Scudder (Department of Zoology, University of British Columbia), K. Fry (Secretary of the Entomological Society of Alberta), and D. Shpeley (University of Alberta). In addition, we extend our sincere thanks to Dr. Scudder for his assistance in verifying the identification and instar of our specimen. We also thank P. Swain (District Manager, Cypress Hills District) for giving us permission to use the map of Cypress Hills Interprovincial Park in Fig. 1, and $P$. Walsh for reviewing the manuscript. This work was conducted as part of 'Bioassays and Biomonitoring' (BI 405), a course offered in the Environmental Monitoring and Protection program at Lakeland College, Vermilion, Alberta.

1. Clifford HF (1991) Aquatic Invertebrates of Alberta. University of Alberta Press, Edmonton, AB.

2. Sites RW, Polhemus JT (1994) Nepidae (Hemiptera) of the United States and Canada. Annals of the Entomological Society of America 87:27-42.

3. Maw HEL, Foottit RG, Hamilton KGA, Scudder GGE (2000) Checklist of the Hemiptera of Canada and Alaska. NRC Research Press, Ottawa, ON.

4. Parker D, Phillips I (2007) Collection records of three aquatic bugs (Heteroptera); pygmy backswimmer (Pleidae), water scorpion (Nepidae) and marsh treader (Hydrometridae) for Saskatchewan, Canada. Blue Jay 65:143-148.

5. Pennak RW (1978) Freshwater Invertebrates of the United States. (2 $2^{\text {nd }}$ edn.). John Wiley and Sons, New York, NY.

I cannot endure to waste anything so precious as autumnal sunshine by staying in the house. 